\title{
Investigation of injection molding process parameters characteristics using RSM approach
}

\author{
Ashish Goyal ${ }^{1 *}$, Vimal Kumar Pathak ${ }^{2}$, Siddharth Ogra ${ }^{3}$, Anand Pandey $^{4}$ \\ ${ }^{1-4}$ Department of Mechanical Engineering, Manipal University, Jaipur, INDIA \\ ${ }^{*}$ Corresponding Author: e-mail: ashish.goyal@ jaipur.manipal.edu, Tel +91-9887174284 \\ ORCID iD: https://orcid.org/0000-0001-8058-6790 (Goyal), https://orcid.org/0000-0003-3542-6530 (Pathak), https://orcid.org/0000-0003-2854-5080 (Ogra), \\ https://orcid.org/0000-0002-2362-1411 (Pandey)
}

\begin{abstract}
The present study analyzes the important characteristics of plastic injection molding machining process. The polypropylene (PP) material has used as a specimen and effect of melt temperature, packing pressure and injection pressure has been investigated on the tensile modulus and elongation. Total 20 experiments have been performed to analyses the results. Response surface methodology (RSM) was adopted for optimization of injection molding process parameters. The experiments were conducted by using central composite design. The analysis of variance (ANOVA) techniques was used for selection of significant and non-significant parameters. The experimental results show that the RSM influence elongation by $87.04 \%$, $11.52 \%, 1.43 \%$ and tensile modulus by $85.35 \%, 11.4 \%, 3.25 \%$.
\end{abstract}

Keywords: Injection molding; polypropylene; tensile modulus; elongation

DOI: http://dx.doi.org/10.4314/ijest.v12i3.2

Cite this article as:

Goyal A., Pathak V.K., Ogra S., Pandey A. 2020. Investigation of injection molding process parameters characteristics using RSM approach. International Journal of Engineering, Science and Technology, Vol. 12, No. 3, pp. 16-26. doi: 10.4314/ijest.v12i3.2

Received: May 9, 2020; Accepted: June 4, 2020; Final acceptance in revised form: June 20, 2020

\section{Introduction}

Injection molding process is widely used manufacturing process for high capacity making of plastic products at low manufacturing cost. The injection molding process, a high-pressure raw material has added into the mold. Subsequently, under high pressure, the fluid solidifies while cooling. Changyu et al. (2007) have presented an artificial neural network and genetic algorithm approach for optimization of process parameters to produce plastic parts by using an injection molding process. The developed hybrid algorithm model has showed the improvement in the volumetric shrinkage and optimum machining condition. Kumar et al. (2013) and Tidke et al. (2014) performed the experiments to improve the output by controlling the input parameters. The design of experiment methodology was adopted to find the optimum value of input parameters. Stanek et al. (2011) investigated the injection molding process parameters to reduce the defect. The parameters used were input velocity, displacement, pressure, fill time, packing pressure, cooling time and total time. It was found that the developed system was a very effective method to optimize help in eliminating defects. Dang et al. (2014) have reviewed the different controlling parameter and optimization approaches for plastic injection molding process to obtain the maximum output during the production of plastic parts.

Kramar et al. (2010) have proposed a fuzzy expert methodology for determine the mechanical properties of parts, fabricated by the injection molding process. The fuzzy approach was optimized using particle-swarm optimization to predict the mechanical properties of molded parts. Masato et al. (2017) focused on the influence of injection molding processing parameters on the 
dimensional accuracy of the polymer composite. A reduction in shrinkage was taken into reflection by studying process parameters on dimensional accuracy. Oliaei et al. (2016) performed experiments to analysis the shrinkage and warpage of the hip liner's UHMWPE, reinforced with nano-hydroxyapatite fabricated by the injection molding process. Kavade et al. (2012) and Lin et al. (2008) applied Taguchi's methodology to optimize the input parameters for injection molding process for polypropylene as the molding material. The methodology could serve in minimizing the cost to the customer by enhancing quality and production aspects. Park et al. (2014) presented the relations among process parameters and response variables, including clamping force and warpage. The parameter was optimized by the response surface methodology (RSM) approach. Through optimal-solution derivation, it can be observed that energy consumption and product quality can be simultaneously optimized. Sorgato et al. (2017) have analyzed the effects of ejection force on the machined cavity texture. For the same two cavity surfaces were machined by micro milling and micro EDM process and effects of ejection forces were investigated.

Rajendra et al. (2018) developed $\mathrm{L}_{16}$ orthogonal array to perform the experiments. The effect of injection molding machining parameters investigated on dark spot and short shots (defect). It was found that the response surface methodology has a significant tool to find the significant parameters. Azdast et al. (2019) has attempted to optimize the defects during the injection molding machining process. The response surface methodology has been adopted to analyses the volumetric shrinkage. The regression model and the interaction plots between the parameters have also been shown in the present work. Goyal et al. (2020) has used RSM approach to identify the significant and non-significant parameters for advance machining process. Manufacturing of precise components by effective utilization of the machining process is a challenging task. The objective of present work is to analyse the effect of melt temperature, packing pressure and injection pressure on the tensile modulus and elongation during the injection molding process by response surface methodology approach. The present work is focused on establishing an effective optimal procedure for approaching the optimal process conditions by using the quadratic model of response surface methodology. The significant parameters were identified by the analysis of variance methodology (ANOVA).

\section{Materials and methodology}

Injection molding process is a recurring process for producing identical components from a master mold and most widely used for production of plastic parts. Polypropylene (PP) material is used for present experimental work and a dumble shaped standard specimen is used for the same. The CAD drawing of the specimen is shown in Figure 1. The polypropylene material has property of high tensile strength, good water absorption, chemical resistance and low density. It is low cost materials that uses for fabrication of plastic and fiber products in automotive manufacturing and aerospace sector. The effects of injection molding parameters such as melt temperature, packing pressure and injection pressure have been analyzed. The tensile modulus and elongation were determined using a universal testing machine (UTM). The specimens were measured/tested by the universal testing machine (Tinius Olsen make and model no-SL series has used). This machine is available at the CIPET itself. The measured values were continuously recorded by software. The slow loading rate of $0.5 \mathrm{~mm} / \mathrm{s}$ has applied and high loading rates of $900 \mathrm{~mm} / \mathrm{s}$ at room temperature $\left(25^{\circ} \mathrm{C}\right)$ has been used. The measured value of tensile modulus and $\%$ elongation was scrutinized by using MiniTab 17 software. The selected process parameters and their levels are presented in Table 1.

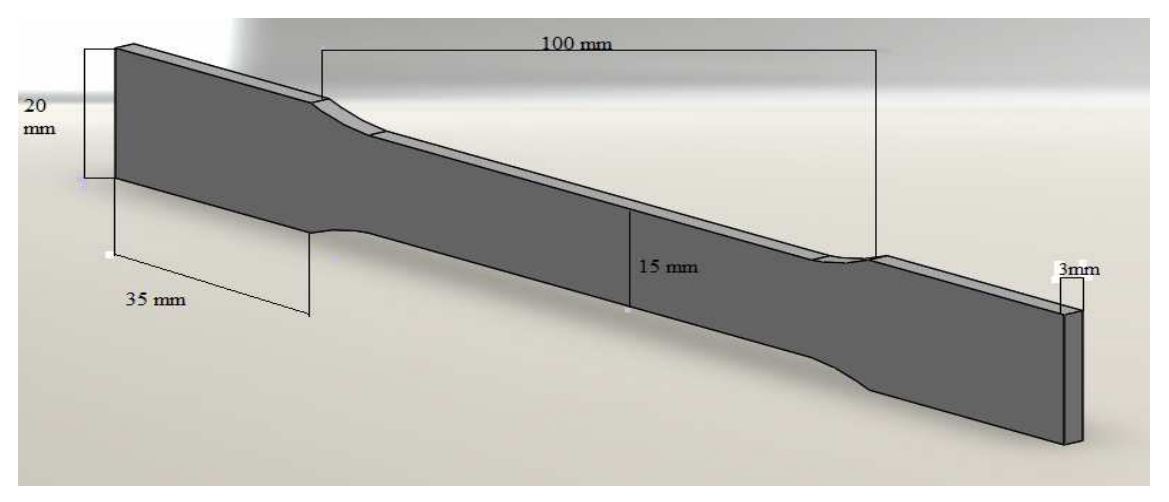

Figure 1. CAD model of a specimen

The working process of injection molding machine is shown in shown in Figure 2. RSM is a collection of statistical and mathematical methods that is useful for modeling and analyzing engineering process. The main objective of RSM is to optimize the response surface that influenced by various process parameters. RSM also quantifies the relationship between the controllable input parameters and the obtained response surfaces. The rotatable RSM approach is a rotatable design that provides response information of the same precision at all points equidistant from the design origin. It is eminently sensible to gather information that is equally good in all directions at the same distance from the centre of the design. An effective alternative to factorial design is 
central composite rotatable design (CCRD). It gives almost as much information as a three-level factorial, which requires many fewer tests than the full factorial design and has been shown to be enough to describe most steady-state process responses. Hence in this study, it was decided to use CCRD to design the experiments. The same approach has been used for the present experimental work. The rotatable design has been obtained for melt temperature, packing pressure and injection pressure to analysis the elongation and tensile modulus.

Table 1. Range and level of process parameters

\begin{tabular}{|l|c|c|c|}
\hline \multirow{2}{*}{ Parameters } & \multicolumn{3}{|c|}{ Levels } \\
\cline { 2 - 4 } & -1 & 0 & 1 \\
\hline Melt Temp $\left({ }^{\circ} \mathrm{C}\right)$ & 190 & 220 & 250 \\
\hline Packing Pressure (psi) & 50 & 90 & 130 \\
\hline Injection Pressure (psi) & 80 & 120 & 160 \\
\hline
\end{tabular}

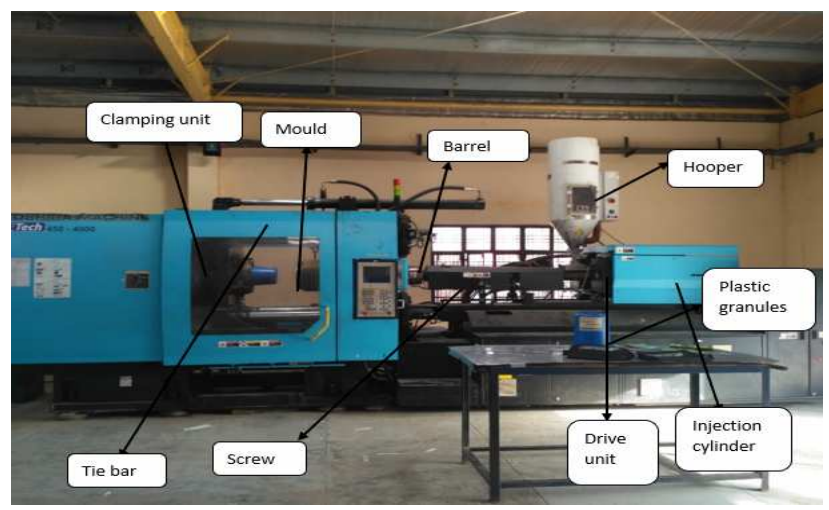

Figure 2. Injection molding machine set up

\section{Results and Discussion}

\subsection{Analysis of elongation}

The orthogonal array of experimental run and measured values for responses i.e. tensile modulus and elongation has presented in Table 2. Figure 3 shows the surface plot of elongation vs packing pressure and injection pressure. In the present work, packing pressure (X-axis) and injection pressure (Y-axis) are the independent variables, and the effect of these parameters investigated on Elongation. It is observed that elongation decreases linearly as the packing pressure is increased and as in case of injection pressure, elongation achieves a high point before decreasing again as keep on increasing the injection pressure. However, it is known that high injection pressure (185 psi) and packing pressures (155 psi) causes overflowing and flash.

Table 2. Design of experimental matrix and experimental results

\begin{tabular}{|l|l|l|l|l|l|}
\hline S. no & $\begin{array}{l}\text { Melt temp. } \\
\left({ }^{0} \mathrm{C}\right)\end{array}$ & $\begin{array}{l}\text { Packing } \\
\text { Pressure (psi) }\end{array}$ & $\begin{array}{l}\text { Injection } \\
\text { Pressure }(\mathrm{psi})\end{array}$ & $\begin{array}{l}\text { Elongation } \\
(\mathrm{cm})\end{array}$ & $\begin{array}{l}\text { Tensile } \\
\text { modulus (MPa) }\end{array}$ \\
\hline 1 & -1 & -1 & -1 & 28.79 & 41.88 \\
\hline 2 & 1 & 1 & -1 & 8.80 & 10.61 \\
\hline 3 & 1 & -1 & 1 & 15.74 & 16.34 \\
\hline 4 & -1 & 1 & 1 & 18.44 & 25.87 \\
\hline 5 & 0 & 0 & 0 & 24.33 & 35.31 \\
\hline 6 & 0 & 0 & 0 & 19.11 & 22.55 \\
\hline 7 & 1 & -1 & -1 & 9.82 & 11.90 \\
\hline 8 & -1 & 1 & -1 & 22.37 & 27.67 \\
\hline 9 & -1 & -1 & 1 & 17.89 & 22.81 \\
\hline 10 & 1 & 1 & 1 & 8.23 & 6.90 \\
\hline 11 & 0 & 0 & 0 & 20.07 & 25.10 \\
\hline 12 & 0 & 0 & 0 & 19.04 & 23.88 \\
\hline 13 & -1.63 & 0 & 0 & 16.88 & 17.27 \\
\hline
\end{tabular}


Table 2 (cont'd). Design of experimental matrix and experimental results

\begin{tabular}{|l|l|l|l|l|l|}
\hline S. no & $\begin{array}{l}\text { Melt temp. } \\
\left({ }^{0} \mathrm{C}\right)\end{array}$ & $\begin{array}{l}\text { Packing } \\
\text { Pressure }(\mathrm{psi})\end{array}$ & $\begin{array}{l}\text { Injection } \\
\text { Pressure }(\mathrm{psi})\end{array}$ & $\begin{array}{l}\text { Elongation } \\
(\mathrm{cm})\end{array}$ & $\begin{array}{l}\text { Tensile } \\
\text { modulus (MPa) }\end{array}$ \\
\hline 14 & 1.63 & 0 & 0 & 6.93 & 3.25 \\
\hline 15 & 0 & -1.63 & 0 & 19.58 & 24.76 \\
\hline 16 & 0 & 1.63 & 0 & 14.78 & 16.82 \\
\hline 17 & 0 & 0 & -1.63 & 10.80 & 16.44 \\
\hline 18 & 0 & 0 & 1.63 & 11.82 & 17.38 \\
\hline 19 & 0 & 0 & 0 & 17.66 & 21.88 \\
\hline 20 & 0 & 0 & 0 & 15.99 & 18.29 \\
\hline
\end{tabular}

Hence, consider a value that experimentally produces an optimized elongation with no defects to the sample part, i.e., packing pressure at $130 \mathrm{psi}$ and injection pressure at $160 \mathrm{psi}$, giving us an elongation of 33.7\%. Figure 4 represents the surface plot of elongation vs melt temp. \& injection pressure. It is noticed that the relation between melt temperature \& elongation and with higher melt temperatures, the elongation tends to decrease. The optimal injection pressure value would be after the peak when the elongation starts falling. In addition, the melt temperature can cue braking of flow and ripples in the product. Hence, the most optimum will be with not the highest melt temperature $\left(269^{\circ} \mathrm{C}\right)$ but the second highest value, i.e., $250^{\circ} \mathrm{C}$ and the value for injection pressure is 160 psi.

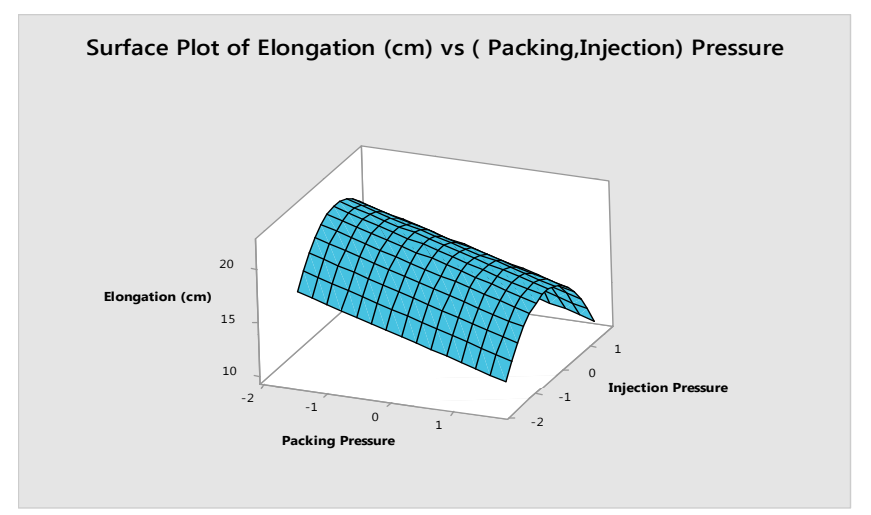

Figure 3. Surface plot of elongation vs packing pressure and injection pressure

Figure 5 represents the surface plot for elongation vs melt temperature \& packing pressure. As observed earlier, the increase in packing pressure causes a linear decrease in the elongation and the relationship between melt temperatures, elongation is linear for very little time, and then elongation begins to fall as the melt temperature increases (Ali et al., 2018). Based on the experimental values, the optimum values of melt temperature and packing pressure for least elongation is $250{ }^{\circ} \mathrm{C}$ and 130 psi respectively.

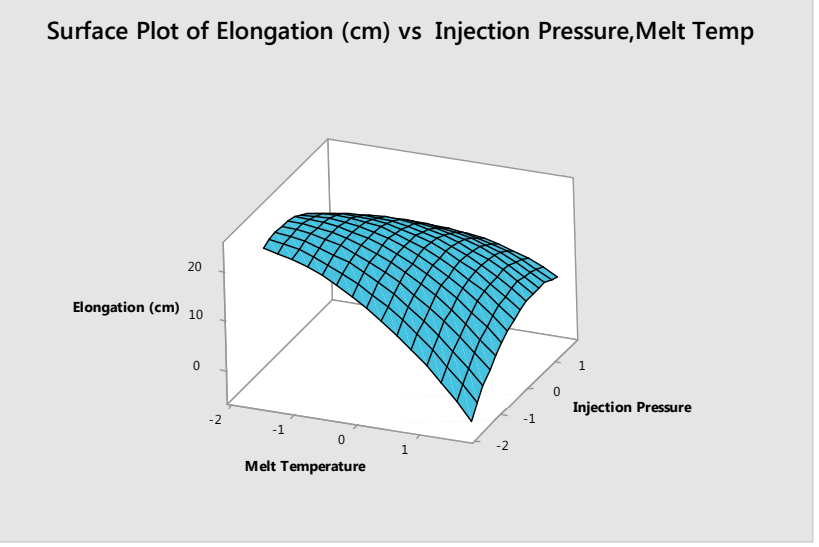

Figure 4. Surface plot of elongation vs melt temp. \& injection pressure 


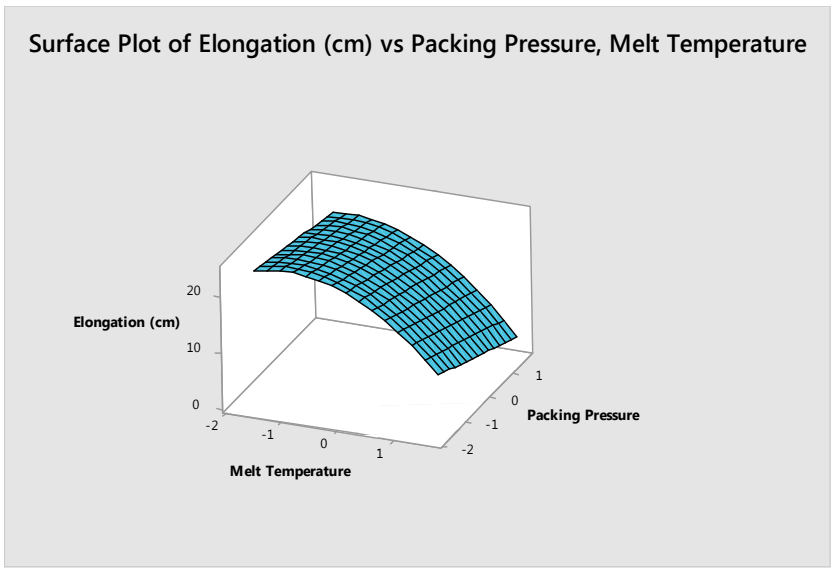

Figure 5. Surface plot for elongation vs melt temperature \& packing pressure

\subsection{Analysis of tensile modulus}

The response i.e., the dependent variable is plotted on the Z-axis while the independent variables are plotted in Figure 6 on the $\mathrm{x}$ and y-axis. In the present case, the tensile modulus is the response to be, measured and packing pressure (X-axis) and injection pressure (Y-axis) are the independent variables, the effect of that is observing on the tensile modulus. For an optimum setting, it requires a sample that does not undergo deformation quickly. Hence, the value of the tensile modulus should be high. Here, it is observed that the packing pressure varies linearly with the tensile modulus and tensile modulus decreases with an increase in the packing pressure. Figure 7 shows the surface plot of tensile modulus vs. packing pressure \& melt temperature. The response, i.e., the dependent variable is plotted on the $\mathrm{Z}$-axis while the independent variables are plotted on $\mathrm{X}$ and $\mathrm{Y}$-axis. It seen that the tensile modulus is decreasing with growth in the melt temperature and with an increase in packing pressure, the tensile modulus is decreasing linearly. The tensile modulus is optimum at $40.51 \mathrm{MPa}$ with a melt temperature of $190^{\circ} \mathrm{C}$ and 50 psi of packing pressure.

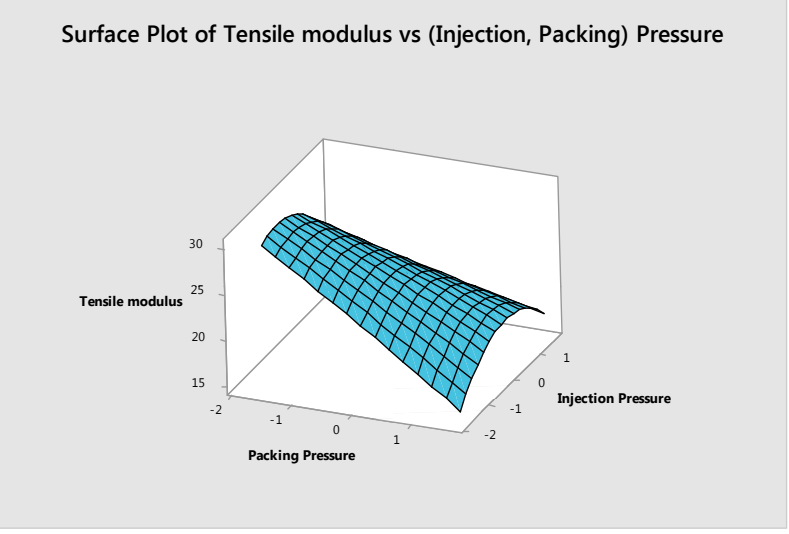

Figure 6. Surface plot of tensile modulus vs packing pressure \& injection pressure

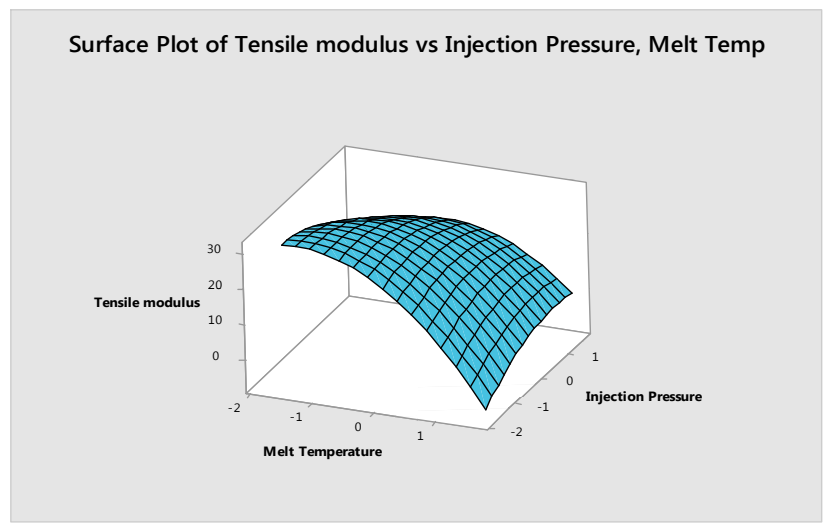

Figure 7. Surface plot of tensile modulus vs injection pressure \& melt temp. 
In the given Figure 8, the melt temperature (X-axis) and injection pressure ( $\mathrm{Y}$-axis) have been considered as independent variables and tensile modulus as the dependent variable (Z-axis). It is observed that tensile modulus remains constant with rise in melt temperature for the initial period before declining tremendously with increasing melt temperature. While in the case of packing pressure, it increases with a steady curve with increasing injection pressure.

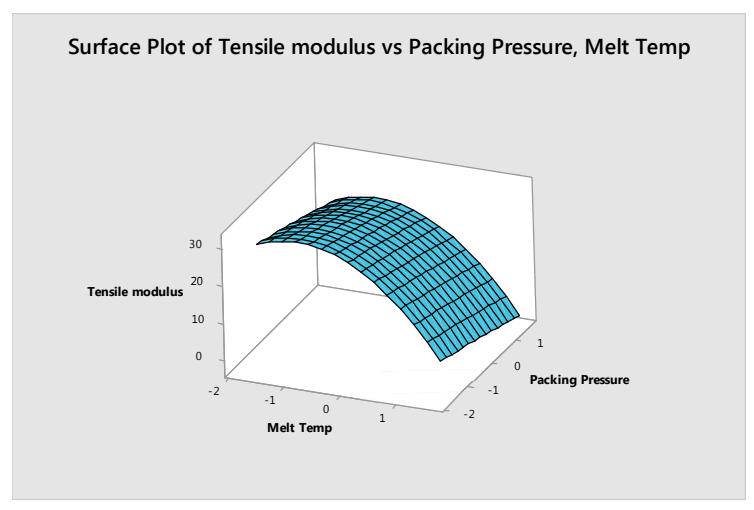

Figure 8. Surface plot of tensile modulus vs packing pressure \& melt temperature

Figure 9 shows the interaction effects of the contour plots showing the interaction effects of the (a) melt temperature and packing pressure for the elongation response and (b) melt temperature and packing pressure for the tensile modulus response, while the remaining parameters are at their respective centre values These plots are graphic representation of the relationships among three numeric variables in two dimensions which correspond to elongation and tensile modulus as a function of two independent variables.
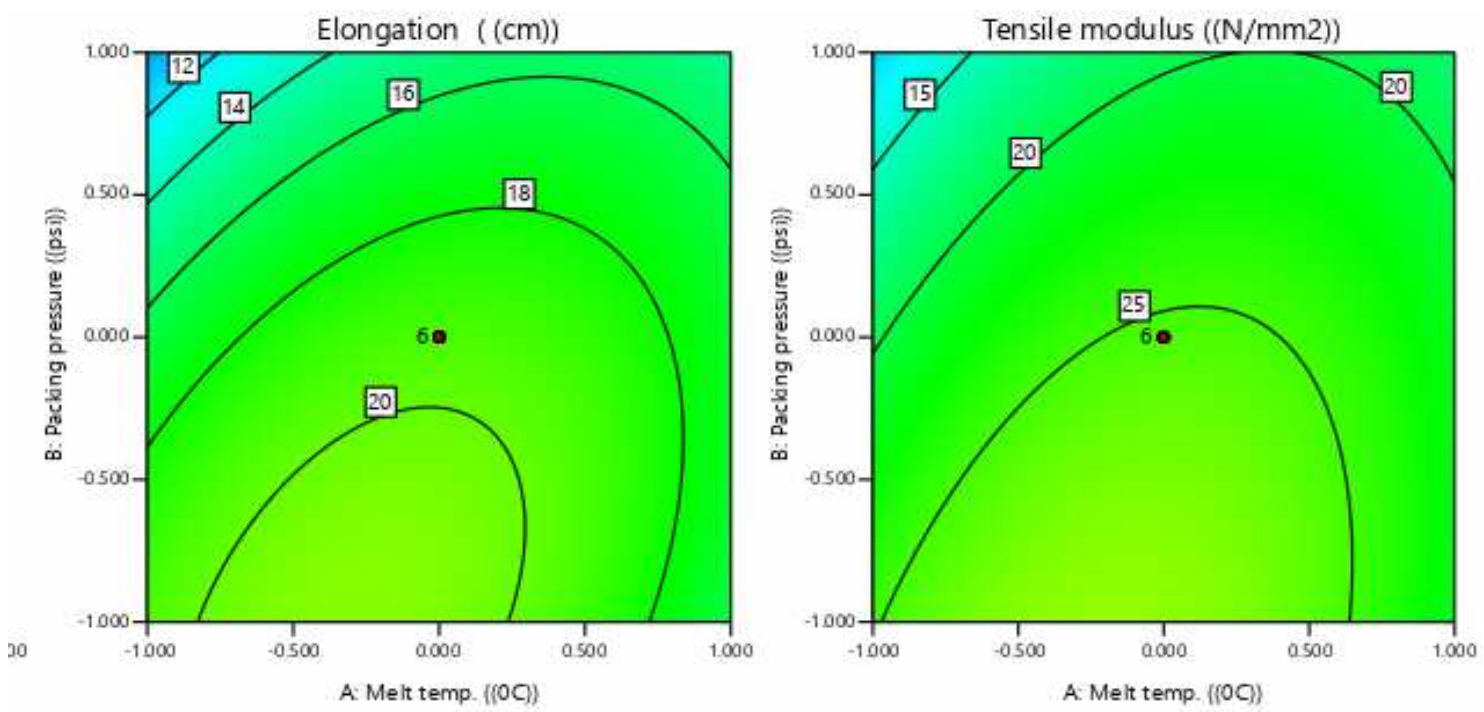

Figure 9. Contour plots showing the interaction effects of the (a) melt temperature and packing pressure for the elongation response and (b) melt temperature and packing pressure for the tensile modulus response, while the remaining parameters are at their respective centre values.

The optimum values of various parameters are plotted in ramp function graph and shown in Figure 10. There is a dot mark in the ramp function graph that indicates the optimal level of process parameter. The highest desirability value is close to the unity and all values lies between 0 and 1 . The graph of actual versus predicted DI values was plotted and shown in Figure 11. It is clearly visible in the graph that most of the values of DI fall proximity to the centre line indicate the better fitness of model. 

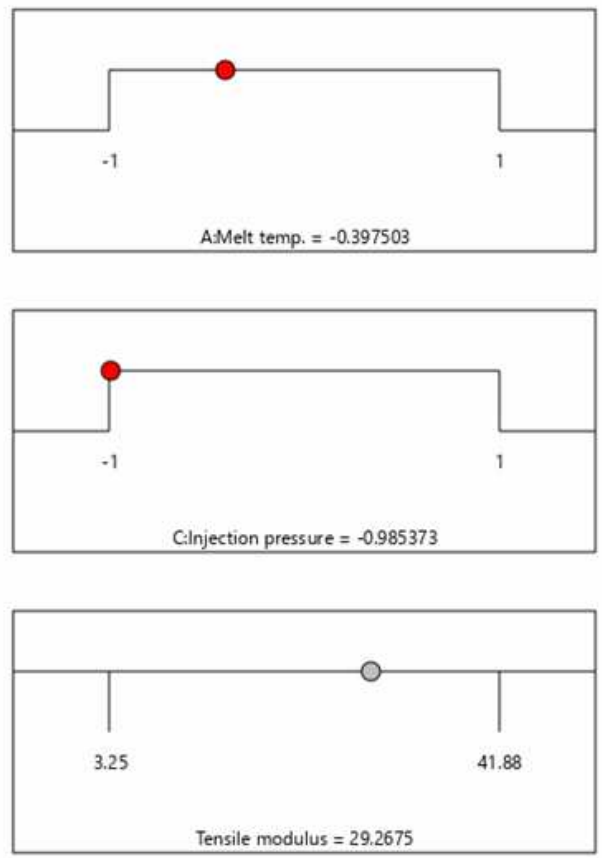

Figure 10. Ramp function graph of desirability
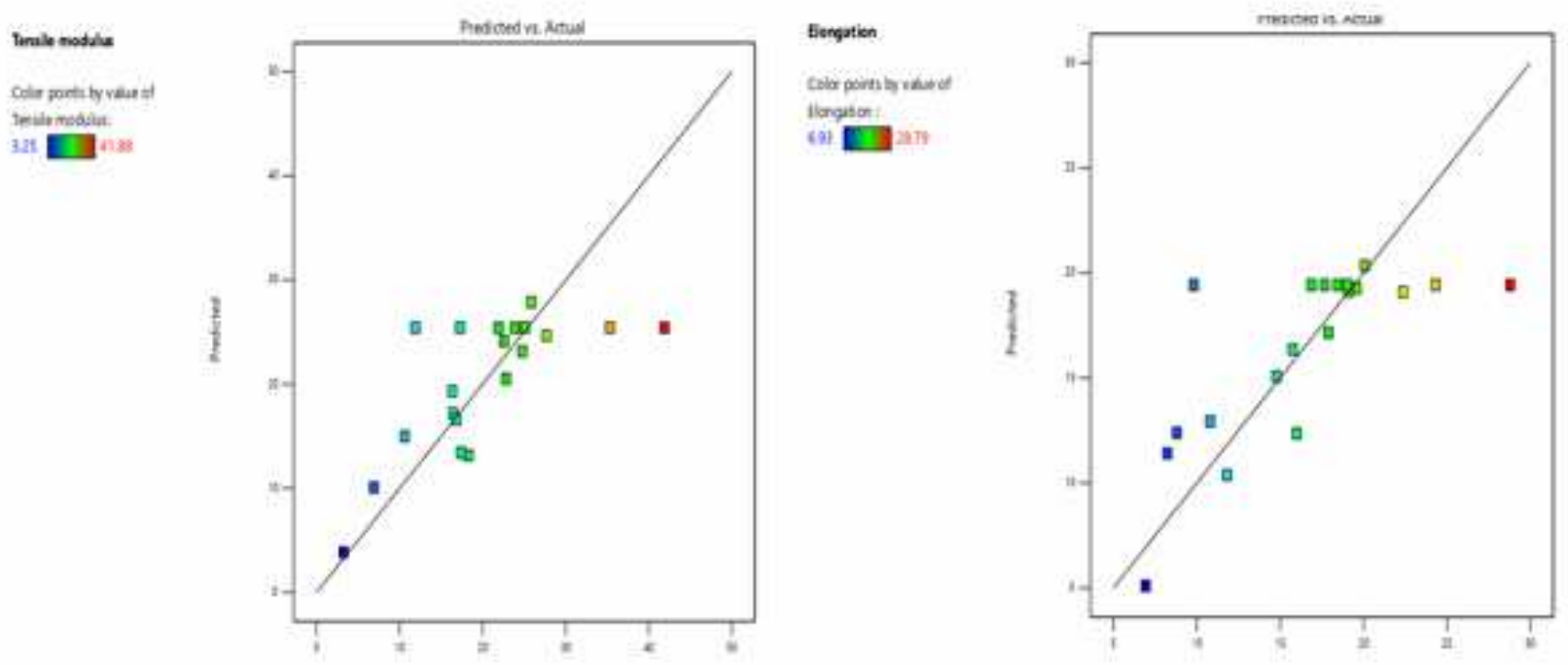

Figure 11. Predicted vs. actual DI values for elongation and tensile modulus

\subsection{ANOVA analysis of elongation and tensile modulus}

Table 3 reveals the ANOVA analysis for the elongation response. In order to analyse the results of the experimental designs, analysis of variance (ANOVA) has adopted. The ANOVA is used to investigate the relationship between a response variable and one or more independent variables. It can be determined if the difference between the average of the levels is greater than what could reasonably be expected from the variation that occurs within the level. As for a model P value, if the model P value is very small (less than 0.05) then the terms in the model have a significant effect on the response. It is a test that compares a term variance with a residual variance. If the variances are close to the same, the ratio will be close to one and it is less likely that the term has a significant effect on the response. In present work as results shown in Table 3, a model F value of 9.08 with a model $\mathrm{P}$ value of less than 0.0002 suggested that the selected model is significant. A P value for the model term A (the melting temperature) also is less than 0.0001 , indicating that the model term A is significant. Similarly, the model terms packing pressure (B) is also significant. In summary, the terms A and B are significant and C is the nonsignificant parameters. The Table 4 shows the ANOVA analysis for tensile modulus. It is seen that the only melt temperature has found the significant (p less than 0.05) parameter and packing pressure and injection pressure has found the non-significant parameters. 
Table 3. Analysis of variance for elongation

\begin{tabular}{|c|c|c|c|c|c|c|}
\hline Source & DF & Adj SS & Adj MS & F- Value & p-Value & Significance \\
\hline Model & 11 & 565.8 & 51.436 & 9.08 & 0.002 & Significant \\
\hline Blocks & 2 & 82.346 & 41.173 & 7.27 & 0.016 & Significant \\
\hline Linear & 3 & 322.161 & 107.387 & 18.95 & 0.001 & Significant \\
\hline Melt temp.(A) & 1 & 280.417 & 280.417 & 49.49 & 0 & Significant \\
\hline Packing pressure(B) & 1 & 37.138 & 37.138 & 6.55 & 0.034 & Significant \\
\hline Injection pressure(C) & 1 & 4.606 & 4.606 & 0.81 & 0.394 & Insignificant \\
\hline Square & 3 & 109.474 & 36.491 & 6.44 & 0.016 & Significant \\
\hline $\mathrm{A}^{* \mathrm{~A}}$ & 1 & 51.915 & 51.915 & 9.16 & 0.016 & Significant \\
\hline $\mathrm{B} * \mathrm{~B}$ & 1 & 0 & 0 & 0 & 0.994 & Insignificant \\
\hline $\mathrm{C}^{*} \mathrm{C}$ & 1 & 64.257 & 64.257 & 11.34 & 0.01 & Significant \\
\hline 2 -way interaction & 3 & 51.818 & 17.273 & 3.05 & 0.092 & Insignificant \\
\hline $\mathrm{A} * \mathrm{~B}$ & 1 & 0.88 & 0.88 & 0.16 & 0.704 & Insignificant \\
\hline $\mathrm{A} * \mathrm{C}$ & 1 & 50.909 & 50.909 & 8.98 & 0.017 & Significant \\
\hline $\mathrm{B} * \mathrm{C}$ & 1 & 0.029 & 0.029 & 0.01 & 0.945 & Insignificant \\
\hline Error & 8 & 45.329 & 5.666 & & & \\
\hline Lack of fit & 5 & 29.815 & 5.963 & 1.15 & 0.484 & Insignificant \\
\hline Pure error & 3 & 15.514 & 5.171 & & & \\
\hline Total & 19 & 611.129 & & & & \\
\hline \multicolumn{7}{|c|}{$\mathrm{R}^{2}=92.58 \%, \mathrm{R}^{2}(\mathrm{adj})=82.38 \%$} \\
\hline
\end{tabular}

Table 4. Analysis of variance for tensile modulus

\begin{tabular}{|c|c|c|c|c|c|c|}
\hline Source & DF & Adj SS & Adj MS & $\begin{array}{l}\text { F- } \\
\text { Value }\end{array}$ & $\begin{array}{l}\mathrm{p}- \\
\text { Value }\end{array}$ & Significance \\
\hline Model & 11 & 1353.39 & 123.035 & 5.14 & 0.014 & Significant \\
\hline Blocks & 2 & 246.22 & 123.112 & 5.14 & 0.037 & Significant \\
\hline Linear & 3 & 799.02 & 266.34 & 11.13 & 0.003 & Significant \\
\hline Melt temp. (A) & 1 & 681.98 & 681.979 & 28.5 & 0.001 & Significant \\
\hline $\begin{array}{l}\text { Packing } \\
\text { pressure (B) }\end{array}$ & 1 & 91.06 & 91.057 & 3.8 & 0.087 & Insignificant \\
\hline $\begin{array}{l}\text { Injection } \\
\text { pressure (C) }\end{array}$ & 1 & 25.98 & 25.985 & 1.09 & 0.328 & Insignificant \\
\hline Square & 3 & 239.36 & 79.787 & 3.33 & 0.077 & Insignificant \\
\hline $\mathrm{A} * \mathrm{~A}$ & 1 & 216.98 & 216.977 & 9.07 & 0.017 & Significant \\
\hline $\mathrm{B} * \mathrm{~B}$ & 1 & 0.15 & 0.146 & 0.01 & 0.94 & Insignificant \\
\hline $\mathrm{C} * \mathrm{C}$ & 1 & 32.13 & 32.131 & 1.34 & 0.28 & Insignificant \\
\hline $\begin{array}{l}2 \text {-way } \\
\text { interaction }\end{array}$ & 3 & 68.78 & 22.926 & 0.96 & 0.458 & Insignificant \\
\hline$A * B$ & 1 & 0.02 & 0.022 & 0 & 0.977 & Insignificant \\
\hline $\mathrm{A} * \mathrm{C}$ & 1 & 58.34 & 58.339 & 2.44 & 0.157 & Insignificant \\
\hline $\mathrm{B} * \mathrm{C}$ & 1 & 10.42 & 10.418 & 0.44 & 0.528 & Insignificant \\
\hline Error & 8 & 191.46 & 23.932 & & & \\
\hline Lack of fit & 5 & 102.82 & 20.563 & 0.7 & 0.663 & Insignificant \\
\hline Pure error & 3 & 88.64 & 29.546 & & & \\
\hline Total & 19 & 1544.84 & & & & \\
\hline \multicolumn{7}{|c|}{$R^{2}=87.61 \%, \quad R^{2}(a d j)=70.57 \%$} \\
\hline
\end{tabular}

Finally, confirmation experiments have been performed using predicted optimal process parameters of injection molding to confirm the feasibility of the predicted process conditions. The outcomes of the confirmation experiment for optimal packing pressure, melt temperature and injection pressure values have been depicted in Table 5. The optimum values of predicted injection molding parameters show an improvement in elongation and tensile modulus by $7.92 \%$ and $3.22 \%$ respectively. 
Table 5. Confirmation experiments

\begin{tabular}{|l|l|l|l|l|l|}
\hline $\begin{array}{l}\text { Process } \\
\text { Parameters }\end{array}$ & $\begin{array}{l}\text { Melt } \\
\text { temp. } \\
\left({ }^{0} \mathrm{C}\right)\end{array}$ & $\begin{array}{l}\text { Packing } \\
\text { pressure } \\
(\mathrm{psi})\end{array}$ & $\begin{array}{l}\text { Injection } \\
\text { pressure } \\
(\mathrm{psi})\end{array}$ & $\begin{array}{l}\text { Elongation } \\
(\mathrm{cm})\end{array}$ & $\begin{array}{l}\text { Tensile } \\
\text { modulus } \\
(\mathrm{MPa})\end{array}$ \\
\hline RSM & 130 & 250 & 160 & 7.28 & \\
\hline & 50 & 190 & 160 & & \\
\hline & 50 & 190 & 80 & & 30.55 \\
\hline Experimental & 130 & 250 & 160 & 8.92 & \\
\hline & 50 & 190 & 160 & & \\
\hline & 50 & 190 & 80 & & 29.57 \\
\hline
\end{tabular}

\section{Conclusion}

In the present work, optimal process parameters were determined for minimum elongation and maximum tensile modulus using rotatable response surface methodology approach. The melting temperature, packing pressure and injection pressure were selected as input parameters to analyses the elongation and tensile modulus during injection molding process.

The following points are drawn as conclusions:

1. Response surface methodology is an efficient optimization methodology in minimizing elongation, maximizing tensile modulus of plastic part manufactured by injection molding process.

2. RSM indicates that melt temperature, packing pressure and injection pressure, influence elongation by $87.04 \%, 11.52 \%$, $1.43 \%$ and tensile modulus by $85.35 \%, 11.4 \%, 3.25 \%$ respectively.

3. Similarly, the most optimum values of the injection molding process parameters were chosen based on values predicted by RSM and it was concluded that, the most optimum process parameters for elongation is packing pressure at 130 psi, melt temperature at $250{ }^{\circ} \mathrm{C}$ and injection pressure at $160 \mathrm{psi}$ to achieve an improvement in elongation of $7.92 \%$. Similarly, the percentage improvement in maximum values of tensile modulus is $3.22 \%$ for the corresponding values of optimum process parameters $50 \mathrm{psi}, 190{ }^{\circ} \mathrm{C}$ and $80 \mathrm{psi}$ for packing pressure, melt temperature and injection pressure.

4. The melt temp and packing pressure has found the significant parameters for the elongation response and for tensile modulus only melt temperature is found the significant parameter.

5. Further study can be performed on the other grade of plastic material to analyses the mechanical properties by other advance optimization techniques such as artificial neural network, fuzzy approach, ANFIS etc.

\section{Acknowledgement}

The authors would like to thank Centre Institute of Plastic Engineering and Technology (CIPET), Jaipur, India for providing the experimental and testing facilities and many thanks to the referees for their advantageous comments and ideas that have significantly enhanced the substance and arrangement of this contribution.

\section{References}

Azdast, T., \& Hasanzadeh, R. 2019. Experimental assessment and optimization of shrinkage behavior of injection molded polycarbonate parts, Materials Research Express, Vol. 6, No. 11, 115334.

Dang, X. P. 2014. General frameworks for optimization of plastic injection molding process parameters, Simulation Modelling Practice and Theory, Vol. 41, pp. 15-27. https://doi.org/10.1016/j.simpat.2013.11.003

Goyal, A., Rahman, H.U. and Ghani, S.A.C., 2020. Experimental investigation and optimisation of wire electrical discharge machining process parameters for $\mathrm{Ni}_{49} \mathrm{Ti}_{51}$ shape memory alloy, Journal of King Saud University-Engineering Sciences. In press. https://doi.org/10.1016/j.jksues.2020.01.003

Kamaruddin, S, Khan, Z A, Foong, S H. 2010. Quality characteristic improvement of an injection molding product made from blends plastic by optimizing the injection molding parameters using taguchi method, International Journal of Plastics Technology, Vol. 14, No. 2, pp. 152-166. https://doi.org/10.1007/s12588-010-0014-2

Kavade, M V, Kadam, S. D. 2012. Parameter optimization of injection molding of polypropylene by using taguchi methodology, IOSR Journal of Mechanical and Civil Engineering, Vol. 4, No. 4, pp. 49-58.

Lin, Y H, Deng, W.J., Huang, C.H., Yang, Y.K. 2008. Optimization of injection molding process for tensile and wear properties of polypropylene components via taguchi and design of experiments method, Polymer - Plastics Technology and Engineering, Vol. 47, No. 1, pp. 96-105. https://doi.org/10.1080/03602550701581027

Sorgato M., Masato D., Lucchetta G., 2017. Effects of machined cavity texture on ejection force in micro injection moulding, Precision Engineering, Vol. 50, pp. 440-448. https://doi.org/10.1016/j.precisioneng.2017.06.019

Masato, D, Rathore, J, Sorgato, M, Carmignato, S, Lucchetta, G. 2017. Analysis of the shrinkage of injection-molded fiberreinforced thin-wall parts, Materials and Design, Vol. 132, pp.496-504. https://doi.org/10.1016/j.matdes.2017.07.032 
Md Ali, M., Mohd Ali, N., Kasim, M., Izamshah, R., Abdullah, Z., Salleh, M., Razak, Z., Sharip, R., \& Yamaguchi, M. 2018. Multi-response optimization of plastic injection moulding process using grey relational analysis based in taguchi method, Journal of Advanced Manufacturing Technology, Vol. 12, No. 3, pp. 87-98.

Naik, D.K. and Maity, K., 2018. Application of desirability function-based response surface methodology (DRSM) for investigating the plasma arc cutting process of sailhard steel, World Journal of Engineering, Vol. 15, No. 4, DOI: 10.1108/WJE06-2017-0125.

Oliaei, E, Heidari, B S, Davachi, S M, Bahrami, M, Davoodi, S, Hejazi, I, \& Seyfi, J., 2016. Warpage and shrinkage optimization of injection-molded plastic spoon parts for biodegradable polymers using taguchi, ANOVA and artificial neural network methods, Journal of Materials Science \& Technology, Vol. 32, No. 8, pp.710-720. https://doi.org/10.1016/j.jmst.2016.05.010

Park, H S, \& Nguyen, T T., 2014. Optimization of injection molding process for car fender in consideration of energy efficiency and product quality, Journal of Computational Design and Engineering, Vol. 1, No. 4, pp.256-265. https://doi.org/10.7315/JCDE.2014.025

Rajendra, K., Vasudevan, H., \& Vimal, G. 2019. Optimization of injection moulding process parameters using response surface methodology, In Proceedings of International Conference on Intelligent Manufacturing and Automation, pp. 445-454. Springer, Singapore.

Lal S.K., Vasudevan H., 2013. Optimization of injection molding process parameters in the molding of low-density polyethylene (LDPE), International Journal of Engineering Research and Development, Vol. 7, No. 5, pp. 35-39.

Stanek, M, Manas, D, Manas, M, \& Suba, O., 2011. Optimization of injection molding process, International Journal of Mathematics and Computers in Simulation, Vol. 5, No. 5, pp. 413-421.

Tidke, Y P, Dhote, A V, \& Patil, C R. 2014. Study and optimization of process parameters in plastic injection molding - a review, International Journal for Research in Applied Science and Engineering Technology, Vol. 2, pp. 58-65.

\section{Biographical notes}

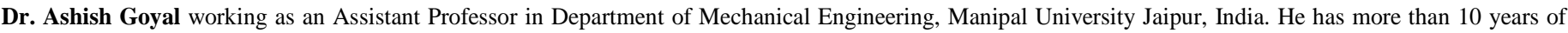

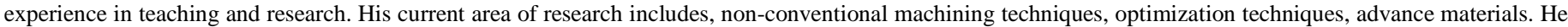
has published various papers in referred international and national journals.

Vimal Pathak received Ph.D. from Malviya National Institute of Technology Jaipur, India in 2017. He is a working as an Assistant Professor in the Department of Mechanical Engineering, Manipal University Jaipur, India. His research interests include multi-objective optimization techniques, Measurements and composite materials. He has published more than 15 papers in referred international journals.

Siddharth Ogra received Bachelor of Technology (B.Tech) degree from Manipal University Jaipur, India in 2018. His research interests are optimization techniques and manufacturing engineering.

Anand Pandey working as a Professor in the Department of Mechanical Engineering, Manipal University Jaipur, India. He obtained PhD from the SLIT, Punjab, India in 2013. He has more than 15 years of experience in teaching and research. His current area of research includes composite materials and non-conventional machining techniques. He has published more than 20 papers in referred international journals. He has also presented more than 25 articles in national and international conferences. He has written few books related to his research work. 